\title{
DIALÉTICA COMO LIBERDADE DE EXPRESSÃO
}

Rodrigo Duarte*

SINTESE - Neste artigo, o autor aborda questöes da liberdade de expressão, restrita não somente por elementos políticos e religiosos, mas também por leis lógicas impessoais, supostamente internas ao próprio pensamento. Em sua abordagem, 0 autor discute com as posições de Wittgenstein e Adorno.

PALAVRAS-CHAVE - Wittgenstein. Adorno. Liberdade. Dialética.
ABSTRACT - This article approaches questions of freedom of speech, restricted not only by political and religious elements, but also by impersonal, logical laws, supposedly inherent in thought itself. In this approach, Wittgenstein's and Adorno's positions are discussed.

KEY WORDS - Wittgenstein. Adomo. Freedom. Dialectics.

Uma das mais evidentes manifestações da liberdade está associada à possibilidade de se expressar aquilo que se pensa, na medida em que configura "liberdade" naquele sentido de confluência entre 0 objetivo e o subjetivo presente na melhor tradição dialética e não apenas enquanto independência do pensamento que não se dá a conhecer por força de constrangimentos externos. De fato, seria impensável falar de liberdade num mundo em que pudéssemos apenas nos movimentar fisicamente em todas as direções, sem que nos fosse permitido, não apenas pensar e sentir, mas - e principalmente - externar nossos pensamentos e sentimentos.

Desde os primórdios da história humana, houve constrangimentos de diversas ordens à total liberdade de expressão: principalmente de origem política e religiosa, ou uma combinação das duas. A principal característica desses constrangimentos é o fato de eles sempre terem sido impostos de fora para dentro, enquanto coerção de um poder constituído cioso da manutenção de suas prerrogativas no seio da sociedade que o abrigava (e/ou abriga). Isso permitiu continuamente que fosse possível a coexistệncia da crença privada discrepante das posições dominantes com uma postura adotada apenas para fins externos, na qual aquelas posições eram endossadas pro forma pelo livre pensador que as solapava, sempre que possivel, na intimidade de seu gabinete de trabalho (especialmente a Idade Moderna está repleta desses casos, de Galileu a Kant, passando por Descartes, Leibniz e muitos outros).

* Professor da UFMG (Universidade Federal de Minas Gerais).

\begin{tabular}{|l|l|l|l|l|l|}
\hline VERITAS & Porto Alegre & v. 44 & n. 4 & Dezembro 1999 & p. 1041-1051 \\
\hline
\end{tabular}


As primeiras décadas do século XX trazem uma novidade no tocante à coerção contra a liberdade de expressão no pensamento: ela tende a se internalizar, como uma espécie de autopunição imposta a si mesmo pelo sujeito - outrora pretendidamente autônomo - da filosofia. O elemento opressor, portanto, agora não é mais um político tirânico ou um autoritário líder religioso, mas impessoais leis lógicas - supostamente internas ao próprio pensamento - o que faz da liberdade formal de expressão, garantida por qualquer constituição democrática, uma caricatura da verdadeira, uma vez que, o que vem à tona, já é previamente filtrado por uma autocensura, cuja origem - como já se disse - não é uma coerção externa, mas algo concebido como conatural à própria atividade de pensar corretamente.

O mais grandioso - e evidente - exemplo dessa autocoibição lógica da liberdade de expressão é o Tractatus logico-philosophicus ${ }^{1}$ (1918) de Ludwig Wittgenstein, que se situa historicamente de modo exato no período mencionado como ponto de inflexão na internalização da censura à expressão filosófica. Tornase necessária, portanto, uma rápida recapitulação de alguns pontos da argumentação apresentada nessa obra, com o objetivo de melhor situar a concepção da dialética enquanto expressão da liberdade.

Para o Wittgenstein do Tractatus, o mundo é composto de fatos, que por sua vez são o subsistir de "estados de coisas" (Sachverhalten); segundo ele, estes são objeto da "figuração lógica", entendida como elemento constitutivo da linguagem, a qual pode efetivamente "afigurar" (abbilden) o mundo. A linguagem é também composta de fatos, na medida em que os signos proposicionais, através dos quais exprimimos o mundo, são também fatos:

"Que o signo proposicional seja um fato é ocultado pela habitual forma de expressão da escrita ou da impressão. Pois na proposição impressa, p. ex., o signo proposicional não parece essencialmente diferente da palavia (então, assim foi possível que Frege tenha chamado a proposição de nome composto)" (3.143).

Uma origem importante da autocensura na filosofia em sua versão wittgensteiniana é a crítica à metafísica, a qual começa por apontar as ambigüidades da linguagem corrente, que são, segundo o filósofo, principalmente de dois tipos: 0 primeiro advém da possibilidade de a mesma palavra significar de vários modos e maneiras diferentes; o segundo diz respeito à situação em que duas palavras, que significam de modo e maneira diferentes, são empregadas da maneira igual numa proposição (3.323). De acordo com ele, seguem-se, dessa forma, as mais fundamentais confusões, das quais a filosofia está cheia (3.324). Para eliminar esses erros, deveríamos, segundo o autor do Tractatus, usar uma linguagem que os evite, na medida em que não empregue o mesmo signo em símbolos diferentes e nem empregue signos, os quais significam de maneira diferentes, de um mesmo modo (3.325).

In: Werkausgabe. Band 1. Frankfurt a. Main, Suhrkamp, 1997. As referências serão feitas, aqui, com o número da proposição entre parêntesis. 
Para Wittgenstein, a linguagem corrente, da qual se serve a filosofia, contém acordos tácitos enormemente complicados, que dificultam seu entendimento (4.002). Para ele, tal como claramente manifesto na proposição 4.003 , a maioria das proposições e questões filosóficas tradicionais não podem ser julgadas falsas ou verdadeiras, mas somente absurdas, sem sentido (unsinnig): "não podemos, portanto, responder a questões desse tipo, mas apenas constatar sua falta de sentido". Tal colocação sobre as proposições da filosofia deve ser contrastada com a proposição 3.24 , que trata de sentenças de tipo científico, nas quais se pode verificar verdade ou falsidade: "A proposição, na qual se fala de algo complexo, será, se ele não existe, não sem sentido, mas falsa".

A crítica à metafísica se baseia na oposição entre um discurso articulado, internamente coerente, e outro em que não há, segundo Wittgenstein, essa articulação, i.é, a filosofia. A proposição 4.032 ajuda a compreender isso: "A proposição é uma imagem da situação de coisas somente na medida que ela é logicamente articulada". Em 4.06, Wittgenstein afirma que uma proposição só pode ser verdadeira ou falsa enquanto é uma figuração da realidade. $O$ restritivo positivismo latente a essa crítica à metafísica aparece claramente quando o autor afirma que: "A totalidade das proposições verdadeiras é toda a ciência natural (ou a totalidade da ciência natural" (4.11). Coerentemente, afirma Wittgenstein, na proposição seguinte, que: "A filosofia não é qualquer das ciências naturais (a palavra 'filosofia' deve significar algo que se encontra acima ou abaixo, mas não ao lado das ciências naturais" (4.111) A essa altura, o autor sugere que a finalidade da filosofia deve ser a crítica e o esclarecimento da linguagem - conforme proposições 4.0031 e 4.112 .

Para o primeiro Wittgenstein, toda proposição possível é construida corretamente; se ela não tiver sentido, é porque não atribuímos denotação a algumas de suas partes constituintes (5.4733). Tal é o caso das proposições metafísicas, nas quais não se atribui denotação a certos signos; daí sua absurdidade. Tal colocação é confirmada por 6.53:

"O método correto da filosofia seria de fato esse: nada dizer, a não ser o que não possa ser dito, i.é, proposições da ciência natural - portanto, algo que nada tem a ver com filosofia. $\mathrm{E}$ então, sempre que alguém quisesse dizer algo metafísico, demonstrar-lhe que ele não atribuiu significado a certos signos em suas proposições."

Wittgenstein não nega propriamente relevância às questões filosóficas, mas, ao frisar a diferença entre o dizer e o mostrar, aponta para o fato de que o mostrar, ao qual se ligam todas as questões éticas e metafísicas, está fora das possibilidades de um discurso articulado, ao qual se alinham as ciências naturais. Esse é o significado da proposição 7: "daquilo que não se pode falar, deve-se calar". Essa proposição pode ser encarada como o supra-sumo daquela autocensura imposta pelo pensamento, mencionada acima, pois uma forma lógica, cuja perenidade não poderia ser dogmaticamente afirmada sob pena de se cair na mais crassa metafísica, não poderia servir de critério definitivo para a exclusão de proposições para cujos termos faltassem definições satisfatórias. 
A problemática associada à aporia fundamental do Tractatus, i.é, a impossibilidade de dizer como deve ser o dizer humano foi exemplarmente abordada por Karl Otto Apel em várias passagens de sua Transformação da Filosofia, ${ }^{2}$ na qual ele procura aproximar as correntes analíticas e hermenêuticas da filosofia contemporânea, tendo como pano de fundo as colocações básicas da filosofia transcendental. Isso ele faz em sintonia com a posição de vários comentadores que consideram a primeira filosofia de Wittgenstein como uma forma de abordagem transcendental, apesar da fundamentação ontológica do Tratactus - sua teoria da afiguração parecer funcionar somente num sistema realista - e de ele recusar o apriorismo sintético de tipo kantiano. ${ }^{3} \mathrm{O}$ próprio Apel pronuncia-se textualmente a respeito dessa possível aproximação, no tocante à delimitação entre o uso legítimo e o abusivo da razão:

"A fronteira entre o que, segundo Kant, é acessivel à razão teórica e o que perfaz a aparência transcendental no uso invasivo da razão, Wittgenstein tenta determinar através da diferenciação lógico-lingüística entre sentido e não-sentido, entre o que se deixa falar e o que somente se mostra" (TF 234).

A aporia a que nos referimos acima, o fato de Wittgenstein poder apenas mostrar - sem poder dizê-lo propriamente - em que bases alguém pode dizer alguma coisa, é percebida por Apel como necessária, nos dois sentidos que o termo pode ter: (1) no sentido de inevitável, pois "nenhuma proposição pode dizer algo sobre si mesma, porque os signos da proposição não podem estar contidos em si mesmos" (3.332); (2) no sentido de indispensável, pois tal aporia pôs à mostra os paradoxos associados ao âmbito filosófico que Wittgenstein ajudou a desbravar. Segundo Apel:

2 Volume 1: Sprachanalytik, Semiotik, Hermeneutik. Frankfurt a. Main, Suhrkamp, 1994. A partir daqui designado por "TF", seguido do número da página, entre parêntesis.

3 Dentre esses comentadores, poderíamos citar, por exemplo, Wolfgang Stegmüller (Hauptströumungen der Gegenwartsphilosophie, Stuttgart, Alfred Kroner Verlag, 1978, pp. 554 ss.). Seria possível até mesmo possível, em que pesem as discrepâncias apontadas, considerar as posições do primeiro Wittgenstein como constituindo uma radicalização do kantismo, no sentido de transpor o idealismo transcendental de Kant do plano da razão para o plano da linguagem. Uma coincidência evidente é que, para ambos autores, o fim da filosofia transcendental é mostrar os limites da teorização plena de sentido, ou os limites da razão teórica.

Para Kant, é científico tudo aquilo que é, em princípio experienciável e tudo que concorda com as formas a priori da experiência (formas de intuição pura e conceitos puros do entendimento). Para Wittgenstein, entretanto, não importa a distinção entre possibilidade lógica e possibilidade teórica: segundo ele não há nem intuições puras nem categorias com as quais o que logicamente pensável deva concordar: objeto de pesquisa teónica pode ser tudo quanto é pensável.

Os limites de uma teorização plena de sentido são, com isso, delimitados por aquilo que podemos descrever numa linguagem perfeitamente lógica: as investigações transcendentais de Kant são, portanto, substituídas por uma análise lógica da linguagem, sendo o sujeito transcendental, para Wittgenstein, aquele que compreende uma linguagem logicamente exata. Em ambos os casos, as limitações impostas à metafísica enquanto conhecimento teórico apontam para direções, senão misticas, pelo menos éticas. Em Kant, abrem espaço para o âmbito da razão prática; em Wittgenstein, para a compreensão da filosofia como "atividade" - Tätigkeit. 
"O mérito do jovem Wittgenstein consiste, a meu ver, no fato de ter tornado visivel de modo conseqüentemente paradoxal os pressupostos metafísicos e as aporias da $1^{\mathrm{a}}$ fase da filosofia analítica da linguagem. O "positivismo lógico", que se esforçou por acolher a crítica wittgensteiniana da metafísica sem seus pressupostos metafísicos, ao contrário - enquanto ideologia -, menos superou esses pressupostos do que os tornou invisíveis" (TF 308).

Com isso, Apel enfatiza mais uma vez o caráter aporético do Tractatus, manifesto no fato de a metafísica, tão ferreamente combatida por Wittgenstein, estar presente em sua obra de juventude mediante a inexistência de denotação para todos os signos proposicionais e de incursão naqueles "acordos tácitos enormemente complicados" que ele denuncia na filosofia tradicional:

"A metafísica teórica é, portanto, segundo o Tractatus de Wittgenstein, a própria transgressão no Tractatus, mesmo que ilustrada com a pretensão apoditica de uma metalinguagem filosófica; isso significa, porém, a tentativa de trazer para a linguagem aquilo que, enquanto condição de possibilidade desse discurso, somente 'se mostra': a forma lógica da linguagem e do mundo descritível" (TF 234).

Entretanto, mais do que a indicação da aporia fundamental do Tractatus, cujo reconhecimento pelo próprio Wittgenstein terá sido a razão da propositura de uma filosofia radicalmente diferente nas Investigações Filosóficas, ${ }^{4}$ importa a Apel sugerir alguma solução para ela, do que resulta sua característica tentativa de aproximar o ponto de vista analítico ao hermenêutico, especialmente àquele de Heidegger, tendo como pano de fundo uma apropriação da filosofia transcendental. Segundo essa aproximação, a mostração da estrutura lógica da linguagem no Tractatus não é autocontraditória se é entendida como um tipo de manifestação do círculo hermenêutico:

"E esse entendimento 'pré-ontológico' implícito na linguagem determina também para Heidegger - não menos do que para Wittgenstein - as condições transcendentais da possibilidade dos objetos da experiência, assim denominadas por Kant. Se pudemos já antes interpretar a distinção wittgensteiniana entre o que se deixa dizer e o que apenas se mostra como expressão da 'diferença transcendental' de Kant, mostra-se também essa diferença como expressão da 'diferença ôntico-ontológica' de Heidegger" (TF 238).

4 Stegmüller (op. cit., p. 565-6) pronuncia-se sobre a passagem de Wittgenstein à sua $2^{2}$ filosofia da seguinte maneira: "Em razão dos argumentos contra o ideal de exatidão, abandona-se a exigência de uma linguagem ideal, com o que o motivo fundamental para a concepção metafísica anterior cai por terra. [...] Faz parte da crítica direta de Wittgenstein à sua filosofia anterior a recusa ao absolutismo e ao atomismo do Tratactus. $\mathrm{O}$ absolutismo se expressa na tese de que o mundo, enquanto fato, é solúvel de apenas um modo em fatos mais simples; o atomismo reside na afirmação de que essa dissolução leva aos fatos mais elementares [...]".

O mundo não seria, portanto, 'em si' estruturado dessa ou daquela forma e não é descrito pela linguagem (correta ou falsamente), mas as possibilidades dessa estruturação surgem somente através da articulação lingüística. Na medida em que a crítica aborda a possibilidade de uma linguagem absolutamente perfeita, ela se dirige também contra o pressuposto ideal de exatidão (essa teria se tomado um ídolo, um mito, ficção metafísica). 
Entretanto, em que pese sua tentativa de "mostrar que a ontologia fundamental de Heidegger pode solucionar o problema fundamental de Wittgenstein, de um discurso filosófico pleno de sentido sobre a forma a prion do discurso e sua relação para com a forma da realidade" (TF 240), Apel se mostra bastante crítico no tocante às repercussões que uma filosofia como a do Tractatus pode ter na concepção de uma subjetividade filosófica no sentido forte do termo, i.é, capaz de uma reflexividade, ocasionando, no limite, o desaparecimento puro e simples do sujeito:

"Aqui mostra-se numa forma extrema o caráter de caso limitrofe da filosofia transcendental wittgensteiniana da linguagem: sendo o sujeito pura e simplesmente idêntico com o projeto formal de mundo da linguagem puramente transcendental, elimina-se toda reflexividade, toda auto-referencialidade do sujeito ao seu projeto lingüistico de mundo. Tudo ocorre como se, em geral, não houvesse qualquer sujeito" (TF 242).

É importante ressaltar que, para Apel, a tentativa de aproximar o primeiro Wittgenstein de Heidegger, é parte de um projeto mais amplo: é uma estação obrigatória da "transformação da filosofia" que ele pretende levar a cabo. Objetivo último desse projeto é uma concepção dialética da linguagem que incorpore tanto uma releitura lingüística do ponto de vista transcendental inaugurado por Kant quanto uma dimensão hermenêutica permeada pela crítica da ideologia (essa última enquanto denúncia dos entraves à função comunicativa da linguagem):

"O discurso filosófico sobre a forma lógica da linguagem e, simultaneamente, do mundo não pressupõe de modo algum um ponto de vista exterior à linguagem e ao mundo, mas segue-se tão somente da reflexividade dialética da forma lógica transcendental da linguagem [...]. Acredito, de fato, que essa interpretação da metalinguagem filosófica, inspirada por Hegel, contém a única resposta possivel ao paradoxo do Tractatus e, com isso, à provocação da suspeita wittgensteiniana de falta de sentido contra toda filosofia teórica" (TF 248-9).

Observa-se, entretanto, no desenvolvimento posterior da obra de Apel, um abandono progressivo desse programa mais generoso, que procura superar a aporia do Tractatus com recurso a algumas das mais influentes correntes da filosofia contemporânea, em benefício de um ponto de vista mais "consistente", porém muito mais restritivo, o qual culmina com a propositura, juntamente com Habermas, de uma teoria do agir discursivo. ${ }^{5}$ A partir daí, em relação a Wittgenstein, a referência passa a ser quase que exclusivamente as Investigações Filosóficas, principalmente naquilo em que elas permitiram, mediante a colaboração de Austin e Searle, o surgimento de uma teoria dos atos de fala que, como se sabe, é vital tanto para a ética discursiva de Apel quanto para a teoria da ação comunicativa de Habermas.

5 De fato, os textos que chamam Heidegger à baila ocorrem principalmente no início de década de 60 e os que já se situam principalmente de um ponto de vista da pragmática transcendental, rumo à elaboração da ética discursiva, surgem principalmente em fins da década de 60 e inícios da de 70, num corte que coincide, aproximadamente com o primeiro e o segundo volume de Transformation der Philosophie (Frankfurt a.M., Suhrkamp, 1994), respectivamente. 
Da parte desse último, surgiram, aliás, críticas extremamente duras a uma posição filosófica que, curiosamente, como se verá, permite um enquadramento a meu ver ainda insuperado da aporia do Tractatus: refiro-me à Dialética Negativa de Theodor Adomo, ${ }^{6}$ especialmente em sua introdução. Seu ponto de partida, aliás coincidente com o de Apel no texto introdutónio da Transformação da Filosofia, é uma reflexão sobre a possibilidade da metamorfose da filosofia em mundo, anunciada na XI tese sobre Feuerbach de Marx:

"Filosofia que, um dia, pareceu superada, permanece vivendo, porque o momento de sua realização foi perdido. O juízo sumário de que ela teria apenas interpretado o mundo, talvez por resignação diante da realidade, degenera-se também em si mesmo, toma-se defaitismo da razão, depois que a transformação do mundo fracassou" (ND 15).

Tal fracasso associa-se, segundo Adomo, não apenas ao já pressentido malogro do socialismo real, mas também a uma espécie de interiorização do procedimento instrumental no seio do próprio pensamento, a qual força o "introvertido arquiteto de pensamentos" a ir morar "atrás da lua que os extrovertidos técnicos confiscaram" (idem). Partindo-se dessa posição, surge, entretanto, a pergunta: qual filosofia merece ser preservada ou mesmo restaurada? Para Adorno estariam excluídas de antemão tanto aquele tipo de filosofia que apenas estende ao âmbito do pensamento o processo de divisão do trabalho industrial, quanto aquele que extrapola o caráter de independência do construto racional com relação à realidade, considerados igualmente por Adomo uma ingenuidade inadmissível à filosofia:

"Só a filosofia que se livra dessa ingenuidade vale ainda a pena continuar a ser pensada. Sua auto-reflexão crítica não deve porém submeter-se diante das mais altas elevações de sua história. Nela seria de se perguntar se - $\theta$ como - ela, depois da queda da hegeliana, ainda é possível, assim como Kant o fez sobre a possibilidade da metafísica após a crítica ao racionalismo" (ND 16).

De interesse para nosso propósito, aqui, é constatar que a filosofia, no sentido invocado por Adorno, se consolida a partir da afirmação de que, contra a proposição 7 do Tractatus Logico-Philosophicus de Wittgenstein, segundo a qual "do que não se pode falar, deve-se calar", a tarefa filosófica primordial é "dizer o que não se deixa dizer" (ND 21). Para Adorno, a contradição latente nessa exigência - que poderia ser classificada por Habermas de "performativa" na medida em que, no interior de uma logicidade bastante estrita e limitada, ela seria auto-anulante - é aquela da própria filosofia, "antes que ela se enrede nas suas contradições singulares" (idem).

Frankfurt a. Main, Suhrkamp, 1985. A partir daqui, designado por "ND", seguido do número da página, entre parêntesis. Quanto às duras criticas de Habermas, elas ocorrem especialmente em $O$ Discurso filosófico da Modemidade (Frankfurt a. Main, Suhrkamp, 1985), onde ele tenta anular inteiramente o esforço crítico de Horkheimer e Adomo em relação à sociedade capitalista tardia, cunhando, para isso, a expressão "contradição performativa", i.é, a radicalização da crítica à racionalidade instrumental como auto-anuladora da possibilidade de qualquer crítica por perder o solo a partir do qual possa realizá-la: "Horkheimer e Adorno encontram uma outra opção, atiçando e mantendo aberta a contradição performativa de uma crítica ideológica que se. aplica sobre si mes. ma, se eles não querem mais ultrapassá-la teoricamente. Depois do fato de que - no nível alcançado pela reflexão - toda tentativa de estruturar uma teoria deveria flutuar no vazio, eles abrem mão da teoria e praticam ad hoc a negação determinada, estabelecendo-se, com isso, contra uma fusão de razão e poder, que preenche todas as fendas" (op. cit., p. 154). 
Essa posição de Adorno em relação à proposição 7 do Tratactus, aparece também - mais detidamente explicada - num conjunto de palestras proferidas em Frankfurt nos semestres de verão de 1962 e de inverno 62/63 agrupadas sob o título de "Terminologia Filosófica":?

"Acredito, porém, que essa famosa proposição de Wittgenstein é, espiritualmente, de uma vulgaridade indescritivel, porque nela passa-se ao largo daquilo com o que a filosofia principalmente tem a ver: é exatamente o paradoxo desse empreendimento de, com os meios do conceito dizer aquilo que, com os meios do conceito, não se deixa dizer. Isso é apenas possivel pelo medium da linguagem, que faculta, simultaneamente, fixar os conceitos e também modificá-los através do valor relativo que ela lhes atribui."

Pano de fundo desse duro pronunciamento sobre a proposição 7 do Tractatus é o ponto de vista adorniano sobre a linguagem, ${ }^{8}$ ao qual se liga sua concepção bastante específica de expressão. Essa aparece, por exemplo, num trecho dos Três Estudos sobre Hegel, não por acaso novamente associada à crítica da proposição 7 do Tratactus:

"O dito de Wittgenstein: 'daquilo que não se pode falar, deve-se calar', no qual o extremo do positivismo transforma-se no hábito da autenticidade respeitosamente autoritária, e que, com isso, exercita um tipo de sugestão de massa intelectual, é pura e simplesmente antifilosófico. A filosofia poderia ser definida, se pudesse sê-lo, como esforço de dizer daquilo que não se pode falar; ajudar a trazer o não-idêntico à expressão, enquanto a expressão sempre o identifica."

Pode-se perguntar a essas alturas qual seria o conteúdo específico da expressão: o que deve ser expressado? Para Adorno tal conteúdo liga-se à situação de "pré-história" - apesar de todo o progresso científico e tecnológico - experienciada pela humanidade: o radical sofrimento humano, conteúdo propriamente dito da expressão, ${ }^{10}$ torna-se através dessa última uma poderosa arma para 0 alcançamento da verdade filosófica:

“Onde o pensamento está além daquilo em que ele se fixa resistindo, está a sua liberdade. Ela segue o impulso à expressão do sujeito. A necessidade de deixar 0 sofrimento ser pronunciado é condição de toda verdade. Pois sofrimento é objetividade que pesa sobre o sujeito; o que ele experimenta como mais subjetivo - sua expressão - é objetivamente mediado" (ND 29).

Frankfurt a. Main, Suhrkamp, 1985, v. 1, p. 56. Cf. v. 2, p. 183.

Tal concepção de linguagem é uma espécie de secularização da idéia benjaminiana, segundo a qual a linguagem originariamente não comunicava conteúdos extemos a si própria, destinando-se prioritariamente ao ato humano de nomear, de atribuir nomes às coisas, dotadas, por sua vez, de uma espécie de "fala" desprovida de som. Essa atribuição de nomes é a continuação do ato divino de criar a realidade: "O homem é o cognoscente da mesma linguagem em que Deus é o criador" (Waiter Benjamin, Gesammelte Schriften, vol. II-1, Frankfurt a. Main, Suhrkamp, 1991, p. 149). O pecado original degenerou essa linguagem de nomes, emudecendo as coisas e dando origem a uma outra linguagem, "burguesa", dominada pela palavra humana e destinada à comunicação de conteúdos exteriores: dela surgiram os milhares de línguas por nós conhecidas (op. cit., p. $152 \mathrm{ss}$.).

10 O termo Ausdruck (expressão), cujo equivalente latino é expressione, denota igualmente bem no Alemão o sentido de algo que está como que comprimido (gedrückt), latente, e encontra uma saída (Ausgang) por onde rapidamente passa, ocasionando como que uma pequena explosão. 
A necessária contrapartida objetiva da expressão remete a nosso ponto de partida, i.é, à idéia de que ela só pode se realizar inteiramente na medida em que se concretiza dialeticamente enquanto manifestação de algo que diz respeito não apenas àquele que se expressa, mas a uma objetividade que, no limite, se refere à humanidade como um todo. Isso liga-se, por sua vez, a outro momento fundamental na arquitetônica da Dialética Negativa, a saber, a não exterioridade entre o conteúdo do filosofema e sua forma de apresentação (Darstellungsform), ${ }^{11}$ os quais convergem na expressão propriamente dita. Segundo Adorno,

"Isso pode ajudar a explicar porque à filosofia sua expressão não é indiferente e exterior, mas imanente à sua idéia. Seu integral momento de expressão, não conceitual e mimético, só é objetivado através de apresentação - linguagem. A liberdade da filosofia não é outra que a faculdade de ajudar sua não-liberdade a soar (zum Laut zu verhelfen)" (ND 29).

A dialética da expressão na filosofia madura de Adorno poderia quase ser resumida por essa afirmação de que a grande liberdade da filosofia, num contexto histónico muito distante de ser livre, é exatamente poder conceder voz à resistência contra as coerções que o constituem. Entretanto, para o filósofo, essa característica da filosofia só pode se concretizar numa atmosfera de imenso rigor, que não é, de nenhum modo, exterior à expressão, com a qual forma um ativo par dialético indispensável ao exercício da escrita filosófica:

"Expressão e rigor não são para ela [filosofia/rd] possibilidades dicotômicas. Elas necessitam-se reciprocamente, nenhuma é possível sem a outra. A expressão é, através do pensamento no qual ela se esforça - e ele nela - aliviada de sua casualidade. $O$ pensamento só enquanto expresso, através de apresentação na linguagem se torna concludente; o que é frouxamente dito é mal pensado. Através da expressão, o rigor é imposto ao que é expressado" (ND 29).

Curiosamente, a forma sob a qual o rigor reveste a expressão de um modo inarredável é o domínio da retórica, entendida por Adomo não como aquele âmbito em que tradicionalmente ocorrem os maiores abusos no emprego da linguagem, até ela se encontrar inteiramente esvaziada de conteúdo. Para ele, na verdade, a antiga arte da eloqüência deveria ser entendida como aquela disciplina, segundo a qual a consciência das possibilidades expressivas da própria linguagem estão como que inscritas em seu uso mais imediato. Contra uma possivel acusação de rebuscamento vazio na linguagem filosófica, Adorno se posiciona no sentido de lembrar que

1 No tocante a essa convergência entre o aspecto conteudístico e o formal na Filosofia, Adorno faz referência a Nietzsche, no primeiro volume da Teminologia Filosófica (op. cit., p. 56), como um precursor da sua própria posição. Há que se mencionar mais uma vez, entretanto, sua filiação à proposta de Walter Benjamin, o qual afirma, no livro sobre o Drama Barroco Alemão, que a forma do tratado, ao contrário da demonstração matemática e de sua transposição filosófica no sistema, tem seu método caracterizado exatamente pela apresentação (Gesammelte Schriften, v. II-1, Frankfurt a. Main, Suhrkamp, 1991, p. 207 ss.). Em Adomo, a escolha do gênero de escrita filosófica que melhor caracteriza a não exterioridade entre conteúdo e forma de apresentação, embora derivada da concepção benjaminiana, recai sobre o ensaio e não sobre o tratado. Cf. "O Ensaio como Forma", In: Noten zur Literatur, Frankfurt (M), Suhrkamp, 1988, p. 9-33. V. tb. meu texto "A Ensaística de Theodor W. Adorno". In: Adornos. Nove ensaios sobre o filósofo frankfurtiano. Belo Horizonte, Ed. UFMG, 1997. 
“a perseguição ao momento retórico, através do qual a expressão salvou-se no pensamento, não contribuiu menos para sua tecnificação, para sua potencial liquidação, do que o cultivo da retórica sob negligência com relação ao objeto" (ND 65).

O ponto de vista francamente favorável à retórica deve ser entendido como um posicionamento radical contra a produção sistemática do que já foi codificado através do uso repetitivo da linguagem, o qual se difere essencialmente de uma adesão à forma tradicional da retórica - de fato, historicamente, permissiva com relação aos abusos na linguagem. A intenção de Adomo seria exatamente a exigência de captura do objeto por meio de sua expressão, de modo a ficar afastada a possibilidade de sua perda no emaranhado de firulas formais da linguagem: "na dialética, o momento retórico - contra o ponto de vista vulgar - toma o partido do conteúdo" (ND 66).

Para entendermos melhor como funciona a expressão filosófica no sentido pretendido por Adorno - mediada pela concepção de retónica acima mencionada consideremos as seguintes afirmações:

Paranóia é a sombra do conhecimento. ${ }^{12}$

Verdadeiros são apenas os pensamentos que não se entendem a si mesmos. ${ }^{13}$

Toda cultura após Auschwitz, incluindo sua urgente crítica, é lixo(ND 359).

Em todos esses exemplos, selecionados entre inúmeros outros possíveis, parece haver uma contradição do tipo que Habermas qualificou de "performativa", i.é, o que é afirmado é, ao mesmo tempo, implicitamente negado. Vejamos de que maneira.

No quē tange à primeira afirmação: de fato, se [todo] o conhecimento é o lado obscuro de um quadro psíquico como o da paranóia, qual o estatuto do que é afirmado? Se pretende ser conhecimento, então se encontra numa situação de possivel enquadramento numa forma de loucura. Se não pretende sê-lo, então não precisa merecer nossa consideração.

Em relação ao segundo trecho citado: se a essência do nosso pensamento está baseada numa forma de compreensão, como atribuir verdade unicamente àqueles pensamentos incompreensiveis?

No que conceme à terceira passagem: de que lugar se está qualificando a cultura e sua crítica de lixo, a não ser de um ponto de vista interno a elas? Qual seria então o estatuto dessa crítica? Ou não seria nada ou seria também lixo.

Afirmações como as citadas acima, totalmente retiradas do seu contexto e distanciadas da intenção filosófica que as originou, levaram críticos como Habermas $^{14}$ a qualificar Adorno de irracionalista, quando, na verdade, o que está em questão é exatamente denunciar a desrazão que vem se apoderando de um mundo que se pretende totalmente racional.

Dialektik der Aufklärung, Frankfurt a.M., Suhrkamp, 1981, p. 221.

Minima Moralia, Frankfurt a.M., Suhrkamp, 1987, p. 254.

Ver nota 5. 
Esses exemplos de expressão filosófica no sentido objetivado por Adorno mostram exatamente em que medida pode o filósofo - como, de resto, o faz também o artista - suspender temporariamente o predomínio das leis lógicas - que, no geral, são indispensáveis - no sentido de chamar a atenção do seu interlocutor ou leitor para algo extremamente grave, que de outro modo poderia passar despercebido. Sob esse aspecto, o "direito" de a expressão postular a suspensão momentânea da logicidade restritiva se consolida toda vez que essa última não atinge a contundência crítica necessária (ou - o que não é infreqüente - até mesmo se mostrar condescendente) diante de monstruosidades que se possam cometer em seu nome.

Todos os três exemplos dados têm essa característica: o primeiro chama a atenção para a medida em que o conhecimento humano altamente desenvolvido tem dado respaldo técnico a desvarios tais como massacres e genocídios. O segundo aponta para a extrema banalização da linguagem atingida pelos meios comunicação de massa, os quais dificultam a manifestação de algo novo, ainda não conhecido e mapeado. O terceiro trecho chama a atenção para o fato de que a cultura, enquanto domicílio das mais elevadas manifestações do gênio humano, não pode ficar indiferente ao fato de que milhões de seres humanos foram trucidados com o emprego da mais alta tecnologia nos campos de concentração nazistas.

De posse da compreensão do significado da expressão filosófica como essência da dialética negativa adorniana, restaria ainda perguntar se aquela se constitui apenas na forma específica de operação dessa última; ou se, na verdade, se está diante de um princípio de explicação da atividade filosófica em geral, inclusive daquela que não se pretende dialética de modo algum. Não mais, seguindo a letra da filosofia de Adomo, mas sem abandonar seu espírito, acredito mais fortemente na segunda hipótese, i.é, a expressão como parte integrante de qualquer filosofia, mesmo sem a consciência ou o consentimento de seu sujeito.

Para exemplificar a possibilidade do que estou falando, pretendo indicá-lo em relação à filosofia que foi o ponto de partida dessa discussão: a do Tractatus de Wittgenstein. No meu entender, a aporia contida na proposição 7, antes de poder ser compreendida como parte de um círculo hermenêutico, como quer Apel, torna-se muito mais compreensível enquanto um grandioso exemplo de expressão filosófica, enquanto uma afirmação que, ou porque choca ou porque fere visivelmente algum preceito lógico, move o interlocutor a uma ação específica. Assim como o próprio Wittgenstein foi levado a abandonar sua primeira filosofia em direção à pragmática da linguagem que caracteriza a segunda fase de seu pensamento, Adomo esperou de seus interlocutores uma reação forte - positiva ou negativa - diante de suas afirmações chocantes e (aparentemente) contraditórias. $\mathrm{E}$ isso de fato aconteceu, pois, todos os que têm tomado contato com a expressão filosófica adorniana, ou têm se posicionado radicalmente contra o estado de coisas denunciado por ela ou têm recalcado sua consciência na medida em que se aferram à acusação de um suposto defeito formal nela existente. 